\title{
FORMAÇÃO DE PROFESSORES: UMA PROPOSTA DE PESQUISA A PARTIR DA REFLEXÃO SOBRE A PRÁTICA DOCENTE
}

\author{
Wildson Luiz Pereira dos Santos \\ Ricardo Gauche \\ Gerson de Souza Mól \\ Roberto Ribeiro da Silva \\ Joice de Aguiar Baptista
}

\section{RESUMO}

Partindo de reflexões sobre o papel da cultura, discutem-se no presente artigo pressupostos metodológicos da pesquisa em formação de professores. $\mathrm{Na}$ integração ensino-pesquisa-extensão, defende-se um modelo de pesquisa no qual os problemas identificados pelos professores sejam os enfocados em ações de formação continuada. Dessa forma, defende-se a formação continuada em processo que privilegie a reflexão sobre a prática docente.

Palavras-chaves: formação de professores, cultura e pesquisa em formação de professores, reflexão sobre prática pedagógica.

\section{ABSTRACT}

In this paper, we discuss methodology assumptions of research on teacher training, based on reflections on the culture role. We support a research model in which research questions emerge from teachers' concerns of teachers in-service. Likewise, we try to integrate the undergraduate training teacher course from research data collected in community activities of teacher training in-service, in a process that prioritizes the reflection on the teaching practice.

Keywords: teacher training, culture and research and teacher training.

\footnotetext{
Instituto de Química - Universidade de Brasília- wildson@unb.br; gauche@unb.br; gmol@unb.br;
} bobsilva@unb.br; joice@unb.br 


\section{Introdução}

Um dos grandes desafios para as universidades públicas está na formação de educadores para o nível de educação básica, ou seja, na formação de professores que vão atuar no ensino formal, contribuindo para que os nossos jovens exerçam conscientemente a sua cidadania, no que diz respeito a sua formação técnico-científico-cultural.

Nesse sentido, torna-se fundamental o desenvolvimento de pesquisas sobre a formação de professores. Propõe-se, no presente artigo, um modelo de pesquisa que esteja assentado a partir da reflexão sobre a prática em uma integração ensinopesquisa-extensão na formação inicial e continuada de professores.

Defende-se o foco na formação de professores: a inicial, por meio do curso de licenciatura, e a continuada, por meio de atividades de extensão, que incluem cursos e eventos de capacitação. O princípio desse trabalho é a formação pela reflexão sobre a prática pedagógica, por meio de ações de pesquisa e extensão voltadas à mudança dessa mesma prática. Ações desenvolvidas no sentido de atender às necessidades levantadas a partir da prática do professor e, nesse sentido, orientadas por questões advindas da atividade de extensão, sendo os seus resultados alimentadores de deliberações no âmbito do ensino, da pesquisa e da própria extensão. Nessa atividade de reflexão conjunta com o professor, estabelecese um trabalho de cooperação na co-construção de recursos e estratégias de ensino a serem desenvolvidas pelo professor, incluindo a produção de materiais pedagógicos.

\section{Pesquisa e formação de professores}

A relevância do papel do professor na pesquisa, situando-o como sujeito real, concreto - de um fazer docente, no que este guarda de complexidade, importância social e especificidade, inclui dar-lhe a voz que precisa ter na produção de conhecimento sobre sua prática. Ampliam-se, nessa perspectiva, as possibilidades de rompimento do tradicional modelo dos cursos de formação de professores rumo à inserção na realidade escolar.

A influência da formação inicial, pretende-se, assume relevante papel na (re)significação de contextos e práticas culturalmente definidas e defendidas, às 
vezes sob a aparência libertadora e democratizante, por discursos supostamente renovadores, que se esquecem dos principais protagonistas das mudanças, os professores, e, sobretudo, de sua imprescindível autonomia (Gauche, 2001).

O ponto em questão é: qual é o modelo vigente em nossa perspectiva de pesquisa sobre formação de professores: o que parte da voz dos pesquisadores, no âmbito da universidade - desconsiderando ou minimizando, portanto, a relevância do contexto escolar, da cultura escolar, das concepções do professor, do aluno etc. -, ou o que considera como fundamentais e constituintes a cultura escolar, a subjetividade, o professor e os demais envolvidos no processo? A proposta, no presente artigo, é apontar possibilidades de se privilegiar o segundo modelo como norteador teórico-metodológico.

Dessa forma, procura-se construir caminhos de formação que vislumbrem as exigências associadas ao perfil do profissional que se pretende habilitar para a tarefa de educar visando ao exercício da cidadania. Neste, insere-se o desenvolvimento das já citadas categorias de LCT, para o que é requerida uma formação muito mais ampla, que engloba valores e atitudes. Isso vai exigir condições de formação de difícil concepção e operacionalização, desafio constante.

Conforme destacado por Paiva (2003), a questão da formação para 0 exercício de uma prática docente reflexiva tornou-se um tema recorrente nas duas últimas décadas, quando das discussões sobre formação de professores. Tal orientação, ressaltada por Schön (1983), teve maior repercussão no país por meio dos trabalhos de Nóvoa (1992) e Zeichner (1993)², sendo que, na comunidade dos pesquisadores em Ensino de Química, Maldaner (2000) tem-nos trazido significativas contribuições.

Importante destacar nossa concordância com o defendido por Freire (2000): "na formação permanente dos professores, o momento fundamental é o da reflexão crítica sobre a prática" (p. 43). Dessa forma, o que se apresenta é uma proposta de pesquisa em que a reflexão crítica sobre a prática torna-se central nas três atividades intrínsecas e indissociáveis: ensino, pesquisa e extensão. Nessa perspectiva, há sempre a preocupação de que os temas discutidos, as experiências realizadas, as propostas alternativas aplicadas ou elaboradas originem-se da própria

\footnotetext{
${ }^{2}$ Schön, D. The Reflective Practioner: How Professionals Think in Action. New York: Basic Books, 1983. NÓVOA, A. (coord.) Os professores e a sua formação. Lisboa: Publicações Dom Quixote, 1992. Zeichner, K. M. A formação reflexiva de professores: idéias e práticas. Lisboa: Educa, 1993. Apud Paiva (2003).
} 
realidade educacional que caracteriza o processo ensino-aprendizagem de Química sob responsabilidade dos professores envolvidos, muitos deles alunos do curso de Licenciatura.

Ensino, Pesquisa e Extensão, desse modo, formam uma tríade em que ocorrem inter-relações de natureza alimentadora-retroalimentadora. Em uma dimensão social, os componentes da tríade confundem-se, no sentido de consolidar uma reflexão crítica sobre a prática, quer se trate do âmbito das disciplinas de graduação, das atividades de extensão ou das pesquisas realizadas sobre essa temática. Para tal, cabe ressaltar a percepção de se trabalhar, em qualquer das três vertentes, sempre com o professor e não para o professor. Com os licenciandos, e não para os licenciandos.

Dessa forma, a opção teórico-metodológica na pesquisa em Ensino de Química defendida é aquela que privilegia o professor e a cultura escolar. Nessa perspectiva, cultura, ética e subjetividade têm papel preponderante.

A constituição do sujeito professor no contexto da dinâmica educacional é uma das preocupações de Gauche (2001), situando-se a Psicologia como instrumento de compreensão dos aspectos enfocados, especialmente vislumbrando a cultura e o desenvolvimento da subjetividade, ou seja, uma abordagem sociocultural.

O conceito de cultura é detidamente analisado por Bruner (1997), que ressalta seu papel constitutivo. No entender do autor, o pensamento individualista que caracteriza a Psicologia situa os sistemas simbólicos utilizados para construir os significados como existentes a priori. A demora em perceber o que o surgimento da cultura significou para a adaptação e para o funcionamento humanos, transferindo a atenção para o cérebro humano, fisicamente falando, atrasou a compreensão da importância essencial do surgimento, paralelo à evolução morfológica, de "sistemas simbólicos compartilhados, de modos tradicionais de viver e trabalhar em conjunto, em suma, da cultura humana" (Bruner, 1997, p. 22).

O papel constitutivo da cultura configura-se, desse modo, como crucial para o entendimento dos processos de formação de professores, especialmente na ótica psicológica. A Antropologia certamente está calcada na análise desse papel, mas para a Psicologia, há novidades em pressupô-lo e Vygotsky (1968) ${ }^{3}$ certamente se

\footnotetext{
3 "El análises del pensamiento verbal en dos elementos separados, básicamente diferentes, preludia cualquier estudio de las relaciones intrínsecas entre lenguage y pensamiento." (p. 19) "... todas las
} 
notabilizou nessa perspectiva, pelo valor dado ao impacto da linguagem sobre a espécie humana. Vislumbrar a cultura em Psicologia tem três grandes implicações. A primeira refere-se ao aspecto metodológico, pois o argumento constitutivo torna impossível basear-se a construção do conhecimento psicológico apenas no indivíduo. A segunda vincula-se ao processo de organização da Psicologia. 0 significado sendo tornado público e partilhado, ao participarmos da cultura, implica a Psicologia dever ser organizada em torno dos processos de produção e de utilização de significado que nos situam na cultura. A terceira refere-se ao poder da "psicologia popular", como denomina Bruner (1997), que "é um relato cultural do que faz os seres humanos pulsarem", e

não estará preocupada com 'comportamentos', mas com 'ações', sua contrapartida intencionalmente fundada e, mais especificamente, com a ação situada, ações situadas em um cenário cultural e nos estados intencionais mutuamente interagentes dos participantes (Bruner, 1997, p. 27).

A partir desses referenciais teóricos, Gauche (2001) defende um trabalho de pesquisa, dentro da perspectiva psicológica, que busque compreender o sujeito professor, partindo dos significados por ele atribuídos, por meio da análise de seus relatos verbais, reveladores dos mesmos. Isso se coaduna com a proposta de Bruner (1997), na medida em que focaliza "os significados em cujos termos o simesmo é definido tanto pelo indivíduo como pela cultura na qual ele participa" (p. 101), no contexto de sua prática docente.

A análise das possibilidades de superação estrutural das limitações impostas à escola passa, necessariamente, pela autonomia da mesma, que exige autonomia de seus participantes, mormente de seus professores (Contreras, 2002), na negociação de significados individuais e coletivos no âmbito dos espaços escolares. Essa negociação perpassa a objetivação das diferentes interpretações subjetivas, historicamente situadas em contextos culturalmente definidos (Gauche, 2001; Gauche e Tunes, 2002a, 2002b).

A cultura compõe-se dos sistemas conceituais individuais e coletivos, mútua e dialeticamente determinantes. A linguagem situa-se aí como portadora de es una generalización, y estudian la palabra y el significado sin referirse a su proceso evolutivo." (p. 138) 
significados e interpretações, razão pela qual os relatos verbais possuem riqueza indiscutível na compreensão dos significados e das interpretações que produzem e são produzidos no exercício da vida culturalmente situada. Como escreve Engelmann (1997, 1998), o relato verbal é um indicador de consciência, por permitir que se infira a consciência por ele denominada "consciência-mediata-de-outros".

A partir da necessidade, da qual nos fala Bruner (1997), de uma "revolução inspirada na convicção de que o conceito central de uma psicologia humana é o significado, juntamente com os processos e transações envolvidos na construção do significado" (p. 39), entendemos ser necessário pensar em especificidades dos diferentes seres humanos, em suas distintas profissões. Dessa forma, passa a ter significado, para nós, uma análise psicológica do ensinar, do interagir em uma sala de aula, do trabalhar em um contexto escolar etc., assim como outra para o clinicar, para o compor, impedindo uma análise única, supostamente capaz de descrever e de prever aqueles processos na forma de generalizações, enfim, de "leis universais". Isso talvez auxiliasse a haver uma mudança no enfoque normalmente dado às teorias psicológicas, que são "transpostas" para a sala de aula, tornando-se os professores seus "aplicadores" eficientes ou não.

\section{Uma proposta de formação de professores na perspectiva da pesquisa e da reflexão}

Nas ações de educação inicial e continuada de professores, a partir do seu contexto de trabalho, naturalmente surge a necessidade de discussão de estratégias de ensino e de recursos didáticos. Nesse sentido, uma questão preocupante é o significado do ensinar e do aprender e as implicações para as estratégias de ensino adotadas pelos professores. A dissociação entre o ensinar e o aprender está presente tanto no discurso cotidiano como em teorias psicológicas sobre a aprendizagem e sobre o desenvolvimento psicológico. Segundo essa visão, o professor não participa diretamente do processo de aprendizagem do aluno. Essa dissociação, em última instância, liga-se ao modo como se concebe a relação entre aprendizagem e desenvolvimento.

Para a visão histórico-cultural (Vygotsky, 1968), a aprendizagem precede o desenvolvimento. O ensinar e o aprender seriam dois processos indissociáveis, formando uma unidade delimitadora do campo de constituição do indivíduo na 
cultura, o que implica a participação direta do professor na constituição de processos psíquicos do aluno. Assim, o foco da análise sobre o ensino incidiria sobre as funções intrapsíquicas do aluno possibilitadas pelo processo de ensinoaprendizagem. Isto é, sobre as funções psíquicas do aluno que, efetivamente, desdobram-se em possibilidades de desenvolvimento como resultado do processo ensino-aprendizagem.

Ainda conforme essa abordagem, a escola é o lugar da experiência com um novo tipo de conhecimento - aquele que é sistematizado, formal - que não substitui outros tipos (por exemplo, o cotidiano, informal), mas integra-se a eles. A particularidade da atividade escolar encontra-se no fato de que o conhecimento sistematizado cria novas necessidades e propicia o desenvolvimento da consciência reflexiva, isto é, o discernimento e o domínio voluntário do próprio ato de pensar.

A partir desses referenciais, acreditamos que cursos de formação de professores poderiam ser concebidos no sentido de integrar ações de ensinopesquisa-extensão focadas na análise da prática docente. Essa tem sido a experiência que temos vivenciado, a qual tem buscado envolver a análise e a reflexão sobre a prática docente em Química, a identificação e o dimensionamento de problemas, focalizando o aluno, o professor e o objeto de conhecimento no contexto particular da escolar de modo integrado, com vistas à proposição de possíveis soluções dos problemas identificados. Nessa perspectiva, tem-se como uma das principais atividades o desenvolvimento de propostas para o ensino da Química nos diferentes níveis.

No campo da formação inicial de professores, foi concebido e implementado na Universidade de Brasília, a partir de 1993, um curso de Licenciatura diferente do tradicional modelo de currículo, em que a licenciatura nada mais é do que um apêndice do Bacharelado. Na concepção proposta, o currículo tem como princípio a identidade na formação do licenciando. Na proposta, a formação do licenciando ocorre desde o primeiro semestre, sendo que a formação técnico-pedagógica é concretizada em um conjunto de disciplinas de responsabilidade dos docentes da área de Ensino de Química, na qual se vincula conteúdo à discussão metodológica, buscando incorporar a reflexão sobre a prática docente.

Nas disciplinas de ensino de Química, desenvolve-se uma série de atividades em que os alunos que já são professores são solicitados a dar exemplos práticos que estão vivenciando em sala de aula, os quais passam a ser objeto de 
reflexão. Ainda na concepção de trabalho de reflexão sobre a ação, no que diz respeito à formação do denominado professor-pesquisador, os estágios supervisionados proporcionam atividades de análise crítica da prática que está sendo vivenciada.

Para aqueles alunos que ainda não são professores, o espaço escolar é estudado por meio da construção de um porta-fólio como forma de registro das atividades de observação da escola, do professor de Química e dos alunos. O portafólio é também utilizado como estratégia para conhecer a singularidade de cada escola e para reflexão sobre o planejamento de ensino concebido e aquele efetivamente realizado. O planejamento de ensino é concebido para o aluno real da escola e o porta-fólio serve para se fazer a reflexão entre o planejado e o efetivamente realizado, considerando as diferentes variáveis que influenciam a dinâmica de sala de aula. Segundo Penin (1995),

o conhecimento do cotidiano escolar é necessário por duas razões. Primeiro, porque sendo conhecido é possível conquistá-lo e planejar ações que permitam transformá-lo, assim como lutar por mudanças institucionais no sentido desejado. (...) Segundo, porque o cotidiano, sendo conhecido, pode fornecer informações a gestões institucionais democráticas que queiram tomar medidas adequadas para facilitar o trabalho ao nível cotidiano das escolas e melhorar a qualidade do ensino aí realizado (p. 161).

Uma outra atividade curricular importante em que se busca a análise e a reflexão sobre a prática docente é a monografia de graduação, em que os alunos devem fazer uma revisão crítica da literatura sobre algum aspecto teóricometodológico de seu interesse ou apresentar uma proposta de material instrucional de Ensino de Química. Nesse espaço curricular, o aluno tem oportunidade de compreender os fundamentos metodológicos da investigação em Ensino de Química, por meio de uma estratégia que converge para a contribuição ao que poderíamos denominar de constituição do sujeito professor (Silva et al., 2002).

$\mathrm{Na}$ formação continuada, busca-se incorporar ações reflexivas, por meio de assessoria a professores e alunos dos Ensinos Médio e Fundamental. Essas atividades ocorrem no Projeto Integração Universidade-Escola, no qual professores e alunos da educação básica procuram a universidade para solicitar orientações. $O$ 
atendimento é feito por meio de visitas agendadas, nas quais os professores e bolsistas (alunos de graduação em Química) prestam assessoria, a partir das demandas trazidas pelos professores e alunos, em torno de questões conceituais, de atividades didáticas, de atividades experimentais, realização de feiras de ciência etc.

Quando se presta assessoria em serviço a um professor do ensino fundamental ou médio, é possível contribuir para seu aperfeiçoamento, na medida em que se discutem aspectos conceituais e alternativas metodológicas para as situações trazidas por ele. Isso tem sido feito, procurando fazer com que o professor reflita sobre a sua prática para a partir daí se pensar conjuntamente em possíveis ações. Assim, cria-se uma parceria na qual é possível desenvolver projetos e propor novas técnicas e abordagens para o ensino, aumentando sua autoconfiança e disposição para enfrentar desafios (Silva et al., 1997).

Por sua vez, o professor que desenvolve uma relação de parceria com a universidade encontra um espaço aberto para o trabalho de seus alunos no desenvolvimento de projetos, normalmente direcionados a feiras de ciências e cultura. Esses alunos encontram o apoio e orientação para a definição e execução de projetos de cunho científico, social e/ou ambiental. A realização e a apresentação desses trabalhos no ambiente escolar promovem a divulgação do conhecimento produzido, tendo um efeito multiplicador na escola.

No que se refere ao estudo de concepções, são de suma importância aquelas relativas à identificação das crenças de professores sobre o papel da atividade experimental no ensino de Química. As concepções identificadas têm razões de variadas naturezas para justificar o ensino experimental, desde aquelas de cunho psicológico ou estritamente pedagógico, até aquelas oriundas de visões epistemológicas da Ciência diferentes e até mesmo opostas (Tunes et al., 1999).

Nas atividades desenvolvidas, assessorando e dialogando com os professores dos Ensinos Fundamental e Médio, tem-se a oportunidade de ter um contato quase que direto com os problemas relacionados ao ensino de Ciências e Química nesses níveis de ensino. Busca-se nessa atuação fazer uma reflexão conjunta com o professor, visando estabelecer uma parceria, na qual, em vez de se apresentarem respostas prontas para as questões que traz, levantarem-se problemas para serem refletidos em conjunto, identificando e dimensionando 
problemas, focalizando, de modo integrado, o aluno, o professor e o objeto de conhecimento.

Em um outro projeto de produção de livro didático, buscou-se aliar a pesquisa e a extensão em um processo de formação continuada, por meio da produção de material didático (Mól et al., 1998, 2000, 2003; Santos et al., 2003, 2004, 2005). O grande desafio do projeto na produção de material, realizado conjuntamente com professores de ensino médio, é a constante negociação entre a proposição de novas metodologias e a tendência dos professores de reproduzirem concepções de ensino consagradas em sala de aula, mesmo que conflituosas com as novas propostas. Isso significa que o princípio da pesquisa sobre a ação, respeitando o contexto cultural, implica uma opção metodológica que, se por um lado viabiliza a aceitação e inserção de novas propostas no contexto educacional, por outro implica uma negociação, em que nem sempre as propostas idealizadas, nos moldes dos princípios da pesquisa em Ensino de Química, são as predominantes.

\section{Considerações finais}

Assumir o trabalho de extensão de formação continuada de professores como ponto de partida para os nossos problemas de pesquisa, integrando ensino, pesquisa e extensão, em um processo que privilegia a reflexão sobre a prática, representa uma inversão nos moldes tradicionais da investigação, em que os pressupostos são estabelecidos previamente a partir de construtos teóricos já definidos. Isso, no entanto, não reduz o caráter investigativo da pesquisa educacional e não se configura em apenas uma estratégia de convencimento e de inserção no sistema educacional, mas, sobretudo, em um princípio metodológico de postura diante dos professores envolvidos em nossas pesquisas.

Se entendermos que a educação básica tem como meta central a formação de jovens brasileiros para o exercício consciente da cidadania, precisamos compreender o papel do ensino de Química no processo de formação de cidadania e assumir esse desafio, na busca de processos de formação de professores nos quais eles possam desenvolver atitudes e valores, por meio da interatividade em sala de aula. Nessa interatividade, espera-se que as vozes dos alunos sejam contempladas, para que novas visões de mundo sejam assumidas no compromisso 
de construção de uma sociedade igualitária que preserve o valor da vida em nosso planeta. Nesse contexto, o princípio da formação pela reflexão, em que as vozes dos professores são consideradas e respeitadas, nos parece o caminho ideal para os propósitos que defendemos na educação para a cidadania, ainda que tenhamos muitos outros desafios a enfrentar nesse processo. 


\section{Referências}

BRUNER, J. Atos de Significação. Porto Alegre: Artes Médicas, 1997.

CONTRERAS, J. A autonomia de professores. Tradução de Sandra Trabucco Valenzuela. Revisão técnica, apresentação e notas à edição brasileira: Selma Garrido Pimenta. São Paulo: Cortez, 2002.

ENGelmanN, A. Ciência natural e consciência. Psicol. Reflex. Crit. v. 11 n.2 Porto Alegre 1998.

. Principais modos de pesquisar a consciência-mediata-de-outros. Psicol. USP v.8 n. 2, São Paulo, 1997.

FREIRE, P. Pedagogia do oprimido, 17 ed. Rio de Janeiro, Paz e Terra, 1987. . Pedagogia da autonomia: saberes necessários à prática educativa. 16 ed. São Paulo: Paz e Terra, 2000.

GAUCHE, R. Contribuição para uma análise psicológica do processo de constituição da autonomia do professor. Tese (Doutorado em Psicologia). Instituto de Psicologia, UnB, Brasília, 2001.

GAUCHE, R.; TUNES, E. Ética e Autonomia - a Visão de um Professor do Ensino Médio. Química Nova na Escola. São Paulo-SP: v. 15, p. 35 - 38, 2002a.

GAUCHE, R.; TUNES, E. Processo de Constituição da Autonomia do Professor de Química - Uma Nova Perspectiva de Análise Psicológica In: 25a Reunião Anual da Sociedade Brasileira de Química, 2002, Poços de Caldas - MG. Livro de Resumos. SP: SBQ, 2002b.

MALDANER, O. A. A formação inicial e continuada de professores de química. ljuí: Ed. Unijuí, 2000. 
MÓL, G. de S e SANTOS, W. L. P. dos (coords.); CASTRO, E. N. F de; SILVA, G. de S; MATSUNAGA, R. T.; SILVA, R. R. da; FARIAS, S. B.; SANTOS, S. M. de O.; e DIB, S. M. F. Química na Sociedade: projeto de ensino de química em um contexto social, Volume 1, módulos 1 e 2, $1^{\underline{a}}$ e $2^{\underline{a}}$ ed. Brasília, Editora Universidade de Brasília, 1998, 2000.

MÓL, G. de S e SANTOS, W. L. P. dos (coords.); CASTRO, E. N. F de; SILVA, G. de S; MATSUNAGA, R. T.; FARIAS, S. B.; SANTOS, S. M. de O.; e DIB, S. M. F. Química e Sociedade: a ciência, os materiais e o lixo, Química: coleção Nova Geração, módulo 1, suplementado com o Guia do Professor. São Paulo, Editora Nova Geração, 2003.

PAIVA, E. V. A formação do professor crítico-reflexivo. In: PAIVA, E. V. (org.) Pesquisando a formação de professores. Rio de Janeiro: DP\&A, 2003.

PENIN, S. Cotidiano e Escola: a obra em construção. 2 ed. São Paulo: Cortez, 1995. SANTOS, W. L. P. dos e MÓL, G. de S. (coords.); CASTRO, E. N. F de; SILVA, G. de S; MATSUNAGA, R. T.; FARIAS, S. B.; SANTOS, S. M. de O.; e DIB, S. M. F. Química e Sociedade, módulos. 2, 3 e 4 e volume único. São Paulo: Editora Nova Geração, 2003, 2004, 2005.

SILVA, R. R. da, TUNES, E., MÓL, G. de S., SANTOS, W. L. P. dos e GAUCHE, R. Integração da universidade com a escola fundamental e média e a educação continuada de professores. Participação, Revista do Decanato de Extensão da Universidade de Brasília, n² 2, p. 53-58, dez/1997.

SILVA, R. R., GAUCHE, R., BAPTISTA, J. A., MÓL, G. S., SANTOS, W. L. P. Projeto Final dos Alunos do Curso de Licenciatura em Química da Universidade de Brasília: Análise e Avaliação Preliminares dos Resultados Obtidos no Período 1996-2001. In: 25aㅗ Reunião Anual da Sociedade Brasileira de Química, 2002, Poços de Caldas MG. Livro de Resumos. SP: SBQ, 2002. 
TUNES, E.; SILVA, R. R. da; CARNEIRO, M. H. da S.; BAPTISTA, J. A. O professor de ciências e a atividade experimental. Linhas Críticas, Brasília, v. 5, n.1, p. 59-66, jul/dez., 1999.

VYGOTSKY, L. S. Pensamiento y lenguaje. La Habana: Edición Revolucionaria, 1968.

Data de recebimento: 05/12/2005

Data de aprovação:17/05/2006 